\title{
Variation of ambient non-methane hydrocarbons in Beijing city in summer 2008
}

\author{
B. Wang, M. Shao, S. H. Lu, B. Yuan, Y. Zhao, M. Wang, S. Q. Zhang, and D. Wu \\ The State Joint Key Laboratory of Environmental Simulation and Pollution Control, College of Environmental Sciences \\ and Engineering, Peking University, Beijing 100871, China
}

Received: 8 February 2010 - Published in Atmos. Chem. Phys. Discuss.: 25 February 2010

Revised: 29 May 2010 - Accepted: 7 June 2010 - Published: 2 July 2010

\begin{abstract}
In conjunction with hosting the 2008 Beijing Olympics, the municipal government implemented a series of stringent air quality control measures. To assess the impacts on variation of ambient non-methane hydrocarbons (NMHCs), the whole air was sampled by canisters at one urban site and two suburban sites in Beijing, and 55 NMHC species were quantified by gas chromatography equipped with a quadrupole mass spectrometer and a flame ionization detector (GC/MSD/FID) as parts of the field Campaign for the Beijing Olympic Games Air Quality program (CareBeijing). According to the control measures, the data were presented according to four periods: 18-30 June, 8-19 July, 1524 August (during the Olympic Games), and 6-15 September (during the Paralympic Games). Compared with the levels in June, the mixing ratios of NMHCs obtained in the Olympic and Paralympic Games periods were reduced by $35 \%$ and $25 \%$, respectively. Source contributions were calculated using a chemical mass balance model (CMB 8.2). After implementing the control measures, emissions from target sources were obviously reduced, and reductions in vehicle exhaust could explain $48-82 \%$ of the reductions of ambient NMHCs. Reductions in emissions from gasoline evaporation, paint and solvent use, and the chemical industry contributed 9$40 \%, 3-24 \%$, and $1-5 \%$, respectively, to reductions of ambient NMHCs. Sources of liquefied petroleum gas (LPG) and biogenic emissions were not controlled, and contributions from these sources from July to September were stable or even higher than in June. Ozone formation potentials (OFPs) were calculated for the measured NMHCs. The total OFPs during the Olympic and Paralympic Games were reduced by $48 \%$ and $32 \%$, respectively, compared with values in June. Reductions in the OFPs of alkenes and aromatics explained $77-92 \%$ of total OFP reductions. The alkenes and
\end{abstract}

Correspondence to: $\mathrm{M}$. Shao

(mshao@pku.edu.cn) aromatics were mainly from vehicle exhausts, and reductions of vehicle exhaust gases explained $67-87 \%$ of reductions in alkenes and 38-80\% of reductions in aromatics. These findings demonstrate the effectiveness of the air quality control measures enacted for the 2008 Olympics and indicate that controlling vehicular emissions could be the most important measure to improve air quality in Beijing.

\section{Introduction}

As the host of the 29th Olympic Games, Beijing has received serious attention because of air quality problems. Although the levels of ambient $\mathrm{SO}_{2}, \mathrm{NO}_{2}$, and $\mathrm{PM}_{10}$ have been stable or even dropping in the city, ground-level ozone concentrations increased rapidly from 1982 to 2003 (Shao et al., 2006). The Grade II National Ambient Air Quality Standard (NAAQS) for hourly averaged $\mathrm{O}_{3}$ concentration is often exceeded in Beijing city, with non-attainment days reaching about 10\% each year from 1998 to 2006 (Beijing EPB Environmental Quality Communique, 1998-2006). From more recent studies, although the precursors to ozone production, i.e., hydrocarbons and nitrogen oxides $\left(\mathrm{NO}_{\mathrm{x}}\right)$ have been decreasing, the level of surface $\mathrm{O}_{3}$ is still increasing (Tang et al., 2009; Shao et al., 2009a), and high concentrations of ground-level $\mathrm{O}_{3}$ continue to be a major concern.

The ozone formation mechanisms are of increasing interest for Beijing city. According to Zhang et al. (2009), the observed $\mathrm{O}_{3}$ levels are largely formed via local photochemical reactions that are generally hydrocarbon-based processes. Therefore, NMHC plays a key role in $\mathrm{O}_{3}$ formation in Beijing, and controlling NMHCs emissions is crucial for $\mathrm{O}_{3}$ pollution abatement. Actually, the sources of NMHCs in Beijing have been quite intensively investigated (Liu et al., 2005; Lu et al., 2007; Song et al., 2007). As a consequence of very rapid social and economic growth, NMHCs sources in Beijing have significantly changed, and the most

Published by Copernicus Publications on behalf of the European Geosciences Union. 
Table 1. Air quality control measures for the 2008 Olympics.

\begin{tabular}{|c|c|c|c|}
\hline $\begin{array}{l}\text { Control } \\
\text { stages }\end{array}$ & Description of control measures ${ }^{\mathrm{a}}$ & $\begin{array}{l}\text { Sampling } \\
\text { duration }\end{array}$ & $\begin{array}{l}\text { Sample } \\
\text { numbers }\end{array}$ \\
\hline Before 30 Jun & Long-term control measures as usual & 18-30 Jun & $\begin{array}{l}\text { PKU(49); } \\
\text { YLD(19); } \\
\text { CP(24); }\end{array}$ \\
\hline \multirow[t]{8}{*}{ 1-20 Jul } & $\begin{array}{l}\text { The following enhanced controls were implemented: } \\
\text { Vehicle controls: }\end{array}$ & $8-20 \mathrm{Jul}$ & $\begin{array}{l}\text { PKU(38); } \\
\text { YLD(24); }\end{array}$ \\
\hline & 1. YLVs: not allowed to drive throughout Beijing; & & $\mathrm{CP}(23)$ \\
\hline & 2. $30 \%$ of the government-owned vehicles were halted from driving; & & \\
\hline & $\begin{array}{l}\text { 3. Stringent entrance check for express ways: only Euro II (or higher) gasoline } \\
\text { powered vehicles, Euro III diesel powered vehicles, and other vehicles with } \\
\text { specific permits were allowed to enter Beijing; }\end{array}$ & & \\
\hline & Industrial source controls: & & \\
\hline & 1. Gasoline stations: installed low fugitive facilities; & & \\
\hline & 2. Chemical and power plants: halted from production; & & \\
\hline & $\begin{array}{l}\text { 3. Businesses of paint and solvent use: required to operate under sealed condi- } \\
\text { tions, or totally halted from operating. }\end{array}$ & & \\
\hline \multirow[t]{4}{*}{21 Jul-27 Aug } & The following stringent controls were added: & 15-24 Aug & PKU(54); \\
\hline & 1. GLVs: odd-even plate number rule was implemented throughout Beijing; & & $\begin{array}{l}\text { YLD(30); } \\
\text { CP(28); }\end{array}$ \\
\hline & 2. Government owned vehicles: extra $40 \%$ were halted from driving; & & \\
\hline & 3. Cargo trucks: not allowed to drive inside the sixth ring; & & \\
\hline 28 Aug-20 Sep & $\begin{array}{l}\text { The control measures were same as those in the period of } 21 \mathrm{Jul}-27 \mathrm{Aug} \text {, except for } \\
\text { that odd-even plate number rule was only implemented inside the fifth ring. }\end{array}$ & 6-15 Sep & $\begin{array}{l}\mathrm{PKU}(40) \\
\mathrm{CP}(20)\end{array}$ \\
\hline
\end{tabular}

a The major contents of the air quality controls made by Beijing municipal government, the Ministry of Public Security of China, the Ministry of Transport of China, and the Ministry of Environmental Protection of China. The number in parentheses is the number of samples.

striking change comes from vehicular emissions. By June 2008, the total number of vehicles registered in Beijing city had increased to about 3.3 million and is still increasing by more than $10 \%$ per year (Beijing Traffic Management Bureau, http://www.bjjtgl.gov.cn). The huge traffic fleet comprised 21712 buses, about 67000 taxis, 0.35 million yellowlabel vehicles (YLVs, vehicles that fail to meet Euro I standards for exhaust emissions), and almost three million greenlabel vehicles (GLVs, vehicles that meet Euro I standards or higher for exhaust emissions). Gasoline evaporation, paint and solvent use, LPG (liquefied petroleum gas) leakage, and the petrochemical industry are also important hydrocarbon contributors.

To abate ground-level $\mathrm{O}_{3}$ during the 2008 Olympic Games, besides the long-term measures for air quality protection, Beijing implemented a series of stringent short-term air quality control options on major air pollution sources from 1 July to 20 September. The target sources included vehicles, gasoline stations, paint and solvent use, steel factories, chemical factories, power plants, etc. As well as the long-term controls, the measures were carried out in four stages, and detailed information is summarized in Table 1. In keeping with these measures, our measurements were designed over four periods (Table 1). In the following text, these four periods and the corresponding control stages are referred to in the temporal order June, July, August, and September, for easier discussion and comparison.

Recently, several studies on the effects of these control measures have been published. Wang et al. (2009a) reported measurements of $\mathrm{O}_{3}, \mathrm{CO}, \mathrm{NO}_{\mathrm{x}}$, and $\mathrm{SO}_{2}$ during the 2008 Olympics at Miyun, $100 \mathrm{~km}$ from the centre of Beijing, showing significant decreases during August 2008 compared to August 2006 and 2007. Wang and Xie (2009) and Zhou et al. (2009) calculated the reductions in primary gaseous pollutants using "bottom-up" methods, both showing significant declines as a result of the air quality controls implemented during the Olympics. Wang et al. (2009b) reported results from a mobile laboratory, showing obvious reductions in both gaseous and particulate pollutants. 
In the present work, the effects of the control measures were investigated using "top-down" methods. A total of 55 NMHC species were quantified at three different sites in Beijing. The measurements spanned all four stages of implementation of the air quality regulations in 2008. Reductions in both ambient mixing ratios and ozone formation potentials (OFPs) were evaluated. A receptor model, a chemical mass balance model (CMB 8.2), was deployed to calculate contributions from the major sources. Reductions of source contributions were used to explain the declines in ambient concentrations and to identify the major species responsible for the reduction in ozone formation potentials (OFPs). This evaluation may provide an opportunity to explore the future directions for effective control strategies for long-term air quality improvement.

\section{Methods}

\subsection{Sampling sites}

The measurements were carried out at three sites (Fig. 1): PKU, YLD, and CP. The PKU site ( $\left.39^{\circ} 99^{\prime} \mathrm{N}, 116^{\circ} 28^{\prime} \mathrm{E}\right)$ was on the top of a six-storey building on the campus of Peking University in Haidian district in the northwest of Beijing city, about $200 \mathrm{~m}$ north of the fourth ring road, $5 \mathrm{~km}$ west of the National Stadium (the Olympic Park), and $10 \mathrm{~km}$ from the center of Beijing. This site is considered to be representative of a typical urban environment in Beijing (Song et al., 2007; Cheng et al. 2008). The YLD site $\left(39^{\circ} 72^{\prime} \mathrm{N}, 116^{\circ} 80^{\prime} \mathrm{E}\right)$ was on the top of a three-storey building in Tongzhou district on the southeast border of Beijing, about $40 \mathrm{~km}$ from the city center, and located in the network of Jingjintang, Jingjin, and Jingshen expressways (Fig. 1) connecting Beijing with Tangshan, Tianjin, and Shenyang, respectively. This site was considered to be representative of the emissions from heavy transportation between Beijing and other cities. The CP site $\left(40^{\circ} 21^{\prime} \mathrm{N}, 116^{\circ} 11^{\prime} \mathrm{E}\right)$ was on top of a six-storey building on the campus of Peking University in Changping district outside the northwest section of the sixth ring road of Beijing, about $40 \mathrm{~km}$ from the center of the city, and representative of the Beijing municipal background (Lu et al., 2007). This site was also important as an area for some endurance sports in the Olympics (e.g., triathlon), and the athletes might be more at risk from air pollutants.

\subsection{Analysis of NMHCs}

Instantaneous whole air samples were taken using fused silica-lined stainless steel canisters (3.2 L, Entech Instrument, Inc., Simi Valley, CA, USA). The canisters were evacuated $<100$ mtorr and then pressurized to $20 \mathrm{psi}$ with highpurity nitrogen. After three cycles of evacuation and refilling, the canisters were evacuated to $<20$ mtorr for use. The stability of the canister samples has been tested (Liu et al., 2008a). The routine samples were collected at 07:00, 09:00, 14:00, and 17:00 during the day, and we added two more

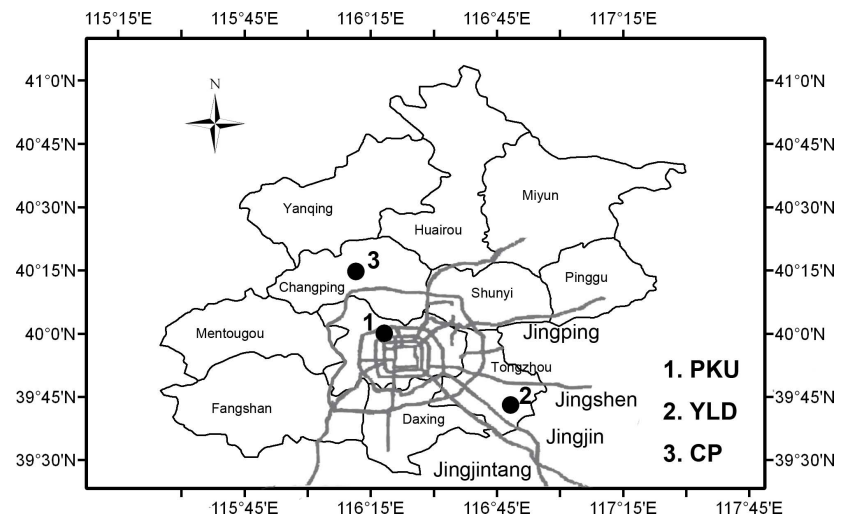

Fig. 1. Locations of the sampling sites used during the CareBeijing 2008 study: 1. PKU site, 2. YLD site, and 3. CP site.

samples at 11:00 and 15:00 at PKU site in August. A total of 331 canisters were collected in this campaign. The numbers of samples from June to September at each site are summarized in Table 1.

The hydrocarbons were quantified using a system comprising a cryogenic pre-concentrator (Model 7100, Entech Instruments, Inc., Simi Valley, CA, USA) and a gas chromatograph (GC, HP-7890A, Hewlett Packard Co., Palo Alto, CA, USA) equipped with a quadrupole mass spectrometer (MSD, HP-5975C, Hewlett Packard), and a flame ionization detector (FID). High-purity helium (He) was the carrier gas, and the flow rate was $1.2 \mathrm{ml} / \mathrm{min}$. Each aliquot of $300 \mathrm{ml}$ from a canister was drawn into the cryogenic trap and cooled to $-180^{\circ} \mathrm{C}$ for pre-concentration. During injection, the trap was resistively heated to $60^{\circ} \mathrm{C}$ within seconds, and a stream of high purity He flushed the trapped VOCs onto the columns. Using a Dean's switch, C2-C3 hydrocarbons were separated on a PLOT (AL/KCL) column $(30 \mathrm{~m} \times 0.25 \mathrm{~mm} \times 3.0 \mu \mathrm{m}, \mathrm{J} \& \mathrm{~W}$ Scientific, Folsom, CA, USA) and detected with FID, and the other species were separated on a DB-624 column $(60 \mathrm{~m} \times 0.25 \mathrm{~mm} \times 1.8 \mu \mathrm{m}, \mathrm{J} \& \mathrm{~W}$ Scientific) and detected with MSD. The GC oven was initially held at $30^{\circ} \mathrm{C}$ for $7 \mathrm{~min}$ and was raised to $120^{\circ} \mathrm{C}$ at $5^{\circ} \mathrm{C} / \mathrm{min}$; after $5 \mathrm{~min}$ the temperature was raised to $180^{\circ} \mathrm{C}$ at $6^{\circ} \mathrm{C} / \mathrm{min}$ and held for $7 \mathrm{~min}$.

A mixture of 55 NMHCs (Spectra Gases, Inc., Newark, New Jersey, USA) was used as a calibration standard for the GC-MSD/FID system (Table 2). Bromochloromethane, 1,4-diflurobenzene, and 1-bromo-3-flurobenzene were used as internal standards for GC/MSD quantification. Daily calibrations were done before analyzing canister samples. The deviations between analytical results of daily calibration and theoretical concentrations were within $10 \%$. The standard deviations of a group of parallel ambient samples were within $15 \%$. The method detection limits (MDLs) of various VOC species ranged from 0.009 to $0.057 \mathrm{ppbv}$. Inter-comparisons of VOC measurements between our lab and other laboratories showed good agreement (Liu et al., 2008a). 
Table 2. The NMHCs quantified in this study.

\begin{tabular}{|c|c|c|c|c|}
\hline \multicolumn{2}{|c|}{ Alkanes (28) } & Alkenes (9) & Aromatics (16) & Others (2) \\
\hline Ethane & Cyclohexane & Ethene & Benzene* & Acetylene* \\
\hline Propane* & 3-methylhexane* & Propene & Toluene* & Isoprene* \\
\hline Isobutane & 2,2,4-trimethylpentane* & 1-butene & Ethylbenzene* & \\
\hline n-butane* & Heptane* & trans-2-butene & $\mathrm{m} / \mathrm{p}$-xylene & \\
\hline Isopentane* & Methylcyclohexane & cis-2-butene & o-xylene & \\
\hline n-pentane* & 2,3,4-trimethylpentane* & 1-pentene & Styrene & \\
\hline 2,2-dimethylbutane* & 2-methylheptane* & trans-2-pentene & Isopropylbenzene & \\
\hline 2,3-dimethylbutane* & 3-methylheptane* & cis-2-pentene & Propylbenzene & \\
\hline 2-methylpentane* & n-octane* & 1-hexene & m-ethyltoluene & \\
\hline Cyclopentane* & n-nonane* & & p-ethyltoluene & \\
\hline 3-methylpentane* & Decane* & & 1,3,5-trimethylbenzene & \\
\hline n-hexane* & Undecane* & & o-ethyltoluene & \\
\hline 2,4-dimethylpentane* & & & 1,2,4-trimethylbenzene & \\
\hline Methylcyclopentane* & & & 1,2,3-trimethylbenzene & \\
\hline 2-methylhexane* & & & 1,3-diethylbenzene & \\
\hline 2,3-dimethylpentane* & & & 1,4-diethylbenzene & \\
\hline
\end{tabular}

* Fitting species used in CMB.

\subsection{CMB model}

The chemical mass balance (CMB V8.2, USEPA) model is a widely used receptor model for source apportionment of air pollutants. The solution of the mass balance equation is based on the linear combination of mixing ratios of the chemical speciation at sources and receptor sites:

$C_{i}=a_{I 1} S_{1}+a_{I 2} S_{2}+\ldots+a_{I j} S_{j}+\ldots+a_{I J} S_{J}$

$(i=1 \ldots I, j=1 \ldots J)$,

where $C_{i}$ is the mass concentration of pollutant $i$ at the receptor site, $a_{I j}$ is the percentage of pollutant $i$ in emission source $j, a_{I j}$ is then the source profile, and $S_{j}$ is the contribution of source $j$ to the receptor site. Therefore, in the CMB model, the source profiles and chemical speciation at the receptor site are measured and used as input data. When the number of air pollutants $(i)$ is equal to or larger than the number of sources $(j)$, the equation series (1) can be solved quantitatively, and from this calculation, the contribution of sources to receptor site $S_{j}$ is derived.

In this work, the number of VOC species was more than 50 , while the number of VOC emission sources was fewer than 10, using the source profiles obtained from our measurements (Liu et al., 2008b). The least squares approach was used to solve equation series (1) to optimize the selection of $S_{j}$ in order to minimize the squared residual deviation $X$ as follows:

$X^{2}=\frac{1}{n-p} \sum_{i=1}^{n} \frac{\left(C_{I}-\sum_{j=1}^{p} a_{i j} S_{j}\right)^{2}}{\sigma_{C i}^{2}+\sum_{j=1}^{p} \sigma_{a_{i j}}^{2} S_{j}^{2}}$, where $\sigma_{C i}^{2}+\sum_{j=1}^{p} \sigma_{a_{i j}}^{2} S_{j}^{2}=V_{\mathrm{eff}, i}$ is the effective squared deviation, $\sigma_{C i}^{2}$ is the measurement deviation of air pollutant concentration $\left(C_{i}\right)$, and $\sigma_{a_{i j}}$ is the uncertainty of measured source profile $\left(a_{i j}\right)$.

\subsection{Meteorological data}

Meteorological data including precipitation (Prec.), wind direction (WD), wind speed (WS), temperature $(T)$, relative humidity $(\mathrm{RH})$, and pressure $(P)$ were continuously recorded during the 4 months by a weather station (LASTEM M7115, LSI- LASTEM, Italy) at the PKU site. In order to compare the data among the four durations and discuss the effectiveness of the air quality controls, the NMHC data have to be carefully selected in order to minimize the meteorological influence. Table 3 summarizes the statistical results of the meteorology data. The lower and upper limits are taken as $10 \%$ and $90 \%$ percentiles of the data in order to exclude extreme conditions. It is interesting to note that the upper and lower limits of Prec. were zero, indicating that the cleaning effect of rain showers was negligible on $80 \%$ of the days measured. Although the $10-90 \%$ percentiles of wind direction covered a wide range of direction, the prevailing wind in the four phases was from north and northwest $\left(315-360^{\circ}\right)$, and most of the recorded wind speeds were below $2 \mathrm{~m} / \mathrm{s}$, indicating that local emissions were the most significant contributors for most of the time, which favors the discussion on the effectiveness of the air quality control measures. Thus, this range of wind direction and speed was set as the first criterion for data selection. The second criterion was set as the range between 10 to $90 \%$ percentiles of $T, \mathrm{RH}$ and $P$ measured in 
Table 3. Summarize of the statistical results of the meteorological condition in the four sampling stages.

\begin{tabular}{lccccccc}
\hline $\begin{array}{l}\text { Sampling } \\
\text { stages }\end{array}$ & Limits & $\begin{array}{c}\text { Prec. } \\
(\mathrm{mm})\end{array}$ & $\begin{array}{c}\text { WD } \\
\left({ }^{\circ}\right)\end{array}$ & $\begin{array}{c}\mathrm{WS} \\
(\mathrm{m} / \mathrm{s})\end{array}$ & $\begin{array}{c}T \\
\left({ }^{\circ} \mathrm{C}\right)\end{array}$ & $\begin{array}{c}\text { RH } \\
(\%)\end{array}$ & $\begin{array}{c}P \\
(\mathrm{hPa})\end{array}$ \\
\hline Jun & lower & 0.00 & 40 & 0.01 & 21.44 & 71.40 & 992.75 \\
& upper & 0.00 & 356 & 1.68 & 27.00 & 95.50 & 996.15 \\
Jul & lower & 0.00 & 117 & 0.03 & 23.92 & 41.00 & 992.80 \\
& upper & 0.00 & 344 & 2.41 & 34.08 & 90.67 & 999.10 \\
Aug & lower & 0.00 & 36 & 0.02 & 21.16 & 37.54 & 992.50 \\
\multirow{3}{*}{ Sep } & upper & 0.00 & 355 & 2.02 & 33.01 & 91.33 & 1000.30 \\
& lower & 0.00 & 73 & 0.00 & 19.94 & 46.96 & 999.10 \\
& upper & 0.00 & 360 & 2.17 & 29.62 & 92.60 & 1010.00 \\
\hline
\end{tabular}

The lower and upper limits are taken as $10 \%$ and $90 \%$ quantiles of respective data in corresponding phase.

Table 4. Mixing ratios and chemical speciations of NMHCs measured in 2008.

\begin{tabular}{|c|c|c|c|c|c|c|c|c|c|}
\hline & & \multicolumn{3}{|c|}{ Mixing ratios of NMHCs (ppbv) } & \multicolumn{5}{|c|}{ Chemical compositions (\%) } \\
\hline & & range & average & STD & alkanes & alkenes & aromatics & acetylene & isoprene \\
\hline \multirow[t]{4}{*}{ PKU } & Jun & $15.9-55.0$ & 34.5 & 9.4 & 46.3 & 19.4 & 20.7 & 12.8 & 0.7 \\
\hline & Jul & $6.5-60.1$ & 28.4 & 16.8 & 53.4 & 16.3 & 18.1 & 9.9 & 2.4 \\
\hline & Aug & $5.3-32.6$ & 21.1 & 11.0 & 56.4 & 16.1 & 17.4 & 7.7 & 2.4 \\
\hline & Sep & $3.8-43.9$ & 25.5 & 8.3 & 58.1 & 19.3 & 11.4 & 9.2 & 1.9 \\
\hline \multirow[t]{3}{*}{ YLD } & Jun & $7.0-43.1$ & 22.5 & 7.8 & 47.6 & 14.9 & 19.2 & 16.7 & 1.7 \\
\hline & Jul & $8.5-28.9$ & 16.1 & 7.7 & 58.2 & 12.1 & 11.4 & 9.3 & 9.1 \\
\hline & Aug & $15.2-24.7$ & 18.3 & 2.6 & 58.3 & 11.6 & 11.1 & 11.9 & 7.1 \\
\hline \multirow[t]{4}{*}{$\mathrm{CP}$} & Jun & $8.9-26.4$ & 19.9 & 7.4 & 50.6 & 18.3 & 13.4 & 17.5 & 0.4 \\
\hline & Jul & $4.7-26.7$ & 17.1 & 10.5 & 51.5 & 16.8 & 11.4 & 11.1 & 9.1 \\
\hline & Aug & $4.8-20.8$ & 10.2 & 4.2 & 53.4 & 14.5 & 9.7 & 10.0 & 12.4 \\
\hline & Sep & $8.1-19.8$ & 12.9 & 3.2 & 59.9 & 14.3 & 9.2 & 10.2 & 6.5 \\
\hline
\end{tabular}

August (listed in Table 3). The NMHC data measured with the meteorological parameters falling within the two criteria were used for further analysis. As a result, 242 data points were chosen for the evaluation on the effects of the air quality restrictions.

\section{Results and discussion}

\subsection{Ambient mixing ratios and chemical speciation}

Ambient mixing ratios and chemical compositions of the measured NMHCs are summarized in Table 4. The levels of NMHCs at PKU site were much higher than those measured at the two suburban sites. On average, the level of NMHCs at $\mathrm{CP}$ was $45 \%$ lower than those measured at PKU. When the stringent controls were implemented, compared with values in June, the average levels of NMHCs were apparently reduced at all sites. For the chemical compositions, alkanes, alkenes, aromatics, acetylene, and isoprene differed among the three sites: PKU had lower isoprene content, YLD had lower alkenes, and CP had lower aromatics. Because each source of hydrocarbons has its own characteristic chemical composition, the differences in chemical composition among the three sites may indicate differences in the source contributions.

At PKU, compared to values in June, average levels of NMHCs were reduced by $18 \%, 39 \%$, and $26 \%$ in July, August, and September, respectively, and chemical compositions also evidently changed. It is interesting to note that the temporal variations of the chemical compositions were different from one group to another, especially for alkenes, aromatics, and isoprene. As each source type has its own fingerprint, the reductions of source emissions from different sources may cause different variations in the chemical composition of ambient NMHCs. These findings may indicate that source emissions at PKU changed greatly in July, August, and September, probably due to the control measures listed in Table 1.

At YLD, although implementation of the stringent controls was the same, the variations of NMHCs differed greatly from those observed at PKU. The average level of NMHCs in August was not reduced compared to July, and the chemical composition was almost the same in July and August, 
reflecting that contributions from the sources additionally targeted in August were not as significant as those controlled in July. As YLD is located at the junction of busy highway transportation between Beijing and other cities, i.e., Tianjin, Tangshan, and Shengyang, the requirements for Euro II gasoline vehicles and Euro III diesel vehicles helped to clean up vehicles entering Beijing, and hence were relevant to reducing NMHC levels at this site, whereas control measures implemented in August mainly targeted the vehicular emissions inside Beijing city, and therefore were not as significant in reducing NMHC levels as the measures taken in July.

At CP, the average ambient mixing ratio of NMHCs and the relative abundance of alkanes, alkenes, aromatics, and acetylene showed very similar temporal variations to those at PKU, probably due to similar variations in source emissions caused by the control measures, indicating the same source origins for the two sites. Compared with the values at PKU, the more reactive groups, i.e., alkenes and aromatics, were generally found in smaller percentages at $\mathrm{CP}$, which could be attributed to photochemical loss during dispersion and transportation of these pollutants, reflecting the municipal background of Beijing.

Isoprene, unlike NMHCs or any other chemical group, had similar temporal variations at the three sites, and the average mixing ratios under the stringent controls were much higher than those in June. This suggests similar emission patterns at the three sites, which were hardly affected by the control measures aimed at the man-made sources (Table 1). In August, isoprene constituted more than $12 \%$ of NMHCs at CP, which could be mainly attributed to CP's having better vegetation coverage than the other sites, and biogenic emissions of isoprene were enhanced in August under higher temperature and light conditions, which was accompanied by decreases of other NMHCs.

Because the controls were all aimed at anthropogenic sources, whereas isoprene was probably from biogenic emissions, concentrations of isoprene were excluded when referring to "reductions of ambient NMHCs," and the remaining species will be called "anthropogenic NMHCs" in the following text. Compared to values in June, on average, at the three sites, reductions of ambient NMHCs were about $35 \%$ and $25 \%$ during the Olympic and Paralympics games, respectively.

To further investigate variations of anthropogenic NMHCs, we compared the levels of three typical species, namely propane, propene, and toluene, measured in 2008 with those measured in previous years (Fig. 2). These measurements were all carried out in summer: Aoti, Old Town, and Wanshou are urban sites, and Daxing, Gu Cheng, Tong Zhou, Liangxiang, and Ming Tombs are suburban sites. The specific information on the measurements, as well as detailed descriptions of the sites, can be found in $\mathrm{Lu}$ et al. (2007) and Shao et al. (2009a, b). To minimize the influence of whether, the data were chosen by the same criteria of meteorology parameters as mentioned in Sect. 2.4.

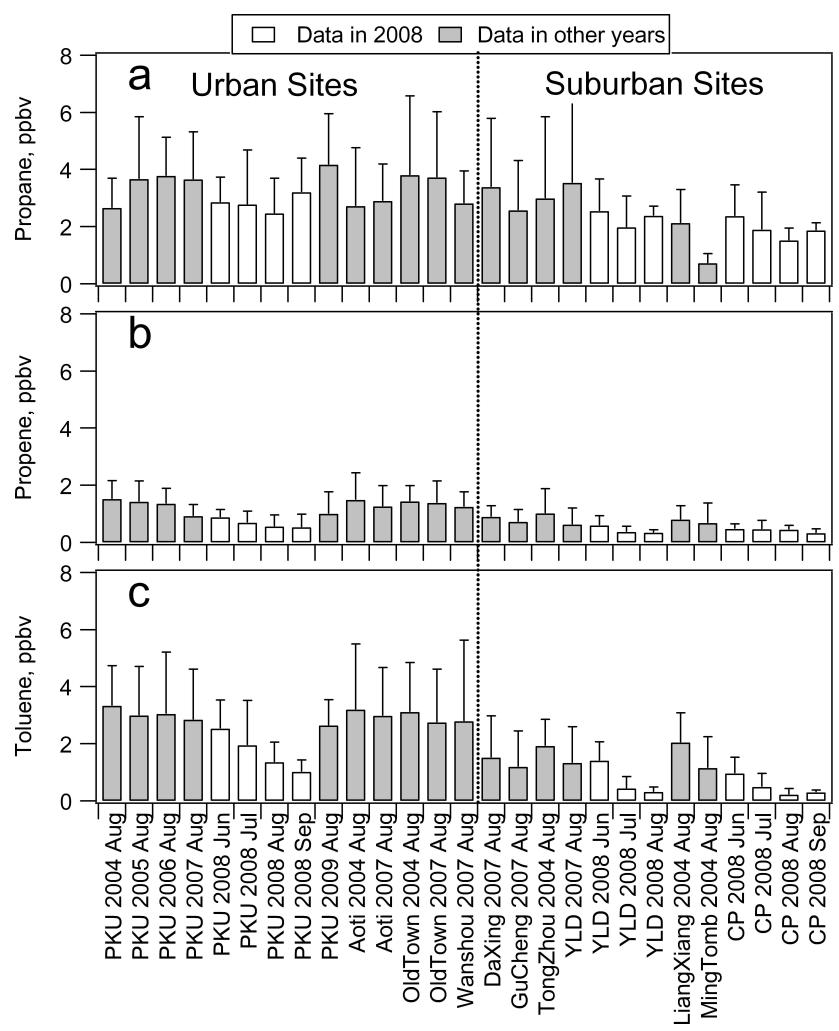

Fig. 2. Variations in the average mixing ratios (in ppbv) of three typical NMHCs measured in Beijing from 2004 to 2009: (a) propane, (b) propene, and (c) toluene.

Propane is a typical tracer for LPG leakage and usage. As shown in Fig. 2a, the average values measured under the stringent controls in 2008 were comparable to those in the other periods. This reflects that LPG is considered as a cleaner fuel and was not controlled in 2008. The levels among urban and suburban sites were comparable, showing more or less homogenous distribution of propane in urban and suburban areas of Beijing city.

The common source for propene and toluene was vehicle exhausts, and ambient toluene may also come from paint and solvent use or chemical industries. As shown in Fig. 2b and c, the average mixing ratios of propene and toluene measured in August and September 2008 were generally lower than those measured in June and July 2008, and also lower than the levels in August in other years. This was true for both urban and suburban sites. The levels of the two species at the urban sites were generally higher than those at suburban sites, suggesting that emissions were greater in urban areas. The change of these two important species proved the effectiveness of the control measures in 2008. Furthermore, it is noteworthy that in August 2009, the mixing ratios of propene and toluene bounded back to levels seen in summer 2007 and previous years. 


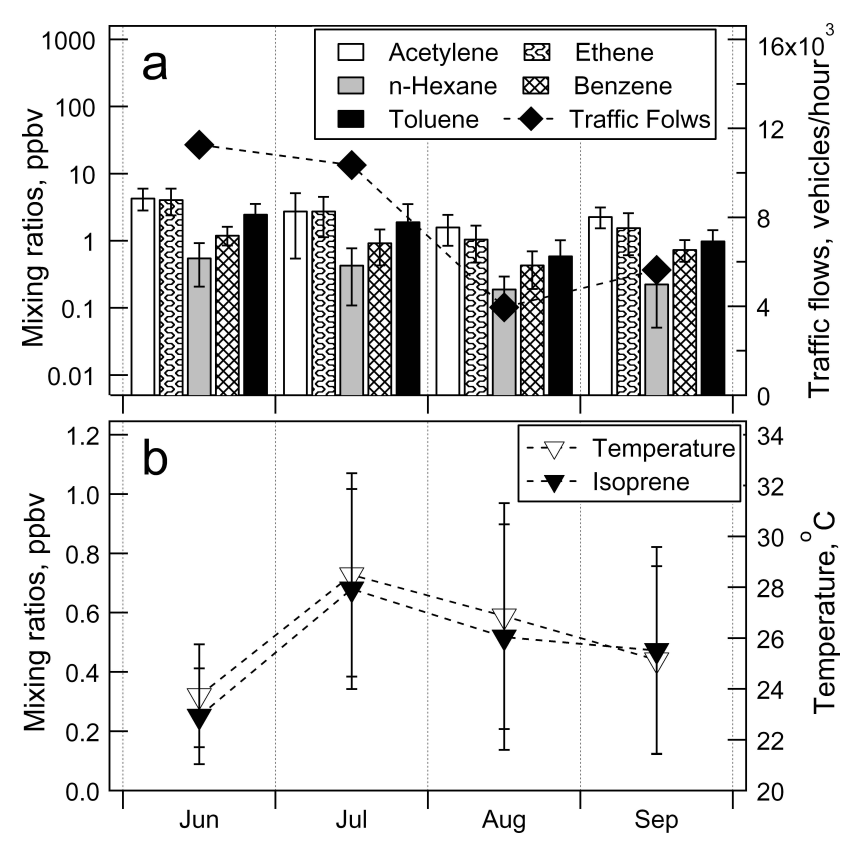

Fig. 3. Associations (a) between the mixing ratios of five NMHC tracers and number of vehicles and (b) between the mixing ratios of isoprene and temperature from June to September at PKU site.

\subsection{Associations between NMHCs and vehicle flow at PKU site}

As listed in Table 1, control of vehicles was one of the key components in the stringent control measures. The traffic numbers during rush hours (08:00-09:00 a.m. and 05:0006:00 p.m.) were counted on the 2nd, 3rd, and 4th ring roads in Beijing. Table 5 presents the NMHC data measured at PKU site from June to September, and some tracers were employed to evaluate the effects of these vehicle control measures.

\subsubsection{Tracers for vehicular exhaust emissions}

Five typical anthropogenic tracers measured at PKU, namely acetylene, ethene, n-hexane, benzene, and toluene, were chosen to explore the relationship between the NMHCs and traffic flows. We also present the variations of isoprene to reflect the change in biogenic emissions.

Figure 3a shows the average traffic flow of the 3 ring roads for rush hours in Beijing. In June, average traffic flow during rush hour was 11264 vehicles per hour, which declined to 10343,3949 , and 5633 vehicles in July, August, and September, respectively. Although the number in September was 43\% higher than that in August, it was still at least $46 \%$ lower than the number in June and July. On average, the number of vehicles was reduced almost $65 \%$ and $50 \%$ during the Olympic and Paralympic Games, respectively. The change of traffic indicated that the control measures in July were much less effective than those in August and September; even more important was that the vehicles running after July were mainly GLVs in the urban area.

Figure 3a shows average levels of the five anthropogenic NMHC species from June to September. An apparent positive correlation was observed between the tracers and traffic numbers. Similar to the variations in traffic, the concentrations were the highest in June and the lowest in August. Compared to values in June, the mixing ratios in August were $63 \%, 74 \%, 65 \%, 64 \%$, and $76 \%$ lower for acetylene, ethene, n-hexane, benzene, and toluene, respectively. Although the values increased in September, they were still 35-54\% lower than those in June and July. It is known that vehicular exhaust is the common source of these species, although they are also emitted from many other sources. Fossil fuel production and leakage contribute n-hexane, benzene, and toluene. Paint and solvent use release benzene and toluene. Industrial and incomplete combustion processes can produce acetylene, ethene, benzene, and toluene. As shown in Fig. 3a, the variations of these species were almost proportional to the reductions of vehicle numbers in each period, indicating that these pollutants were mainly from vehicular emissions, especially GLVs. Moreover, the relative abundance of these speices were very similar in the four months, and as shown in Table 5 the less reactive species (e.g. acetylene and benzene) did not show evident enrichment in total NMHCs in July or August when compared to the more reactive species (e.g. propene and 1-butene), indicating that the reaction with hydroxyl radical could be only a minor factor influencing the changes in the ambient mixing ratios of NMHCs.

Figure $3 \mathrm{~b}$ shows the change of isoprene mixing ratios. Unlike the above-mentioned five tracers, the trend of isoprene was almost opposite to that of traffic numbers, but highly correlated with averaged ambient temperature. Because biogenic emissions are mainly determined by ambient temperature and solar irradiation, it is reasonable to conclude that isoprene was largely contributed from biogenic sources in this study. Barletta et al. (2002) reported that isoprene is also a contributor to vehicular exhausts, but our observations suggest that vehicle emissions played a minor role in isoprene emissions.

\subsubsection{Emission ratios}

The ratios between the mixing ratios of pairs of ambient NMHC species are useful in exploring major sources of selected species. The ratio of the ambient mixing ratios of two hydrocarbons with similar chemical reactivity should be equal to that of their relative emission rates from sources (Goldan et al., 2000; Jobson et al., 2004). In this section, we examine the importance of vehicular emission by analyzing correlations among the NMHC species and comparing them with ratios from known sources. The selected pairs of hydrocarbons are benzene vs. acetylene, trans-2-butene vs. cis-2-butene, ethene vs. toluene, and n-hexane vs. toluene 
Table 5. The levels of NMHC species measured at PKU site from June to September. (Unit: ppbv)

\begin{tabular}{|c|c|c|c|c|c|c|c|c|}
\hline \multirow[t]{2}{*}{ Species } & \multicolumn{2}{|c|}{ Jun } & \multicolumn{2}{|c|}{ Jul } & \multicolumn{2}{|c|}{ Aug } & \multicolumn{2}{|c|}{ Sep } \\
\hline & Averages & STD & Averages & STD & Averages & STD & Averages & STD \\
\hline Ethane & 3.53 & 0.30 & 3.60 & 1.99 & 2.16 & 1.08 & 3.37 & 1.19 \\
\hline Propane & 2.85 & 0.94 & 2.77 & 1.88 & 2.46 & 0.72 & 3.21 & 1.08 \\
\hline Isobutane & 1.47 & 0.81 & 1.57 & 1.10 & 1.49 & 0.69 & 1.88 & 1.24 \\
\hline n-butane & 1.87 & 1.00 & 1.70 & 1.25 & 1.51 & 0.71 & 1.63 & 1.52 \\
\hline Isopentane & 2.03 & 1.07 & 2.14 & 1.35 & 1.80 & 0.78 & 1.99 & 1.19 \\
\hline n-pentane & 0.91 & 0.65 & 0.82 & 0.69 & 0.50 & 0.23 & 0.70 & 0.66 \\
\hline 2,2-dimethylbutane & 0.05 & 0.04 & 0.04 & 0.02 & 0.05 & 0.04 & 0.05 & 0.03 \\
\hline 2,3-dimethylbutane & 0.09 & 0.06 & 0.07 & 0.04 & 0.07 & 0.04 & 0.08 & 0.08 \\
\hline 2-methylpentane & 0.52 & 0.34 & 0.45 & 0.30 & 0.39 & 0.19 & 0.44 & 0.28 \\
\hline cyclopentane & 0.10 & 0.06 & 0.08 & 0.05 & 0.07 & 0.04 & 0.07 & 0.04 \\
\hline 3-methylpentane & 0.34 & 0.22 & 0.33 & 0.22 & 0.31 & 0.18 & 0.35 & 0.22 \\
\hline n-hexane & 0.56 & 0.40 & 0.44 & 0.25 & 0.20 & 1.12 & 0.23 & 0.48 \\
\hline 2,4-dimethylpentane & 0.04 & 0.03 & 0.08 & 0.04 & 0.06 & 0.03 & 0.05 & 0.05 \\
\hline Methylcyclopentane & 0.25 & 0.13 & 0.18 & 0.13 & 0.14 & 0.08 & 0.14 & 0.09 \\
\hline 2-methylhexane & 0.18 & 0.14 & 0.12 & 0.09 & 0.09 & 0.05 & 0.10 & 0.07 \\
\hline 2,3-dimethylpentane & 0.08 & 0.05 & 0.05 & 0.03 & 0.05 & 0.03 & 0.05 & 0.04 \\
\hline Cyclohexane & 0.09 & 0.05 & 0.07 & 0.04 & 0.06 & 0.08 & 0.05 & 0.05 \\
\hline 3-methylhexane & 0.21 & 0.17 & 0.14 & 0.11 & 0.10 & 0.06 & 0.13 & 0.11 \\
\hline 2,2,4-trimethylpentane & 0.03 & 0.01 & 0.02 & 0.00 & 0.03 & 0.03 & 0.02 & 0.02 \\
\hline Heptane & 0.19 & 0.13 & 0.11 & 0.09 & 0.08 & 0.04 & 0.09 & 0.07 \\
\hline Methylcyclohexane & 0.09 & 0.04 & 0.06 & 0.05 & 0.04 & 0.02 & 0.03 & 0.02 \\
\hline 2,3,4-trimethylpentane & 0.03 & 0.04 & 0.02 & 0.01 & 0.02 & 0.02 & 0.01 & 0.01 \\
\hline 2-methylheptane & 0.05 & 0.04 & 0.03 & 0.02 & 0.02 & 0.01 & 0.02 & 0.01 \\
\hline 3-methylheptane & 0.05 & 0.03 & 0.03 & 0.02 & 0.03 & 0.01 & 0.02 & 0.01 \\
\hline n-octane & 0.11 & 0.10 & 0.06 & 0.05 & 0.03 & 0.02 & 0.03 & 0.02 \\
\hline n-nonane & 0.09 & 0.24 & 0.05 & 0.05 & 0.04 & 0.03 & 0.03 & 0.02 \\
\hline Decane & 0.10 & 0.17 & 0.08 & 0.07 & 0.06 & 0.05 & 0.04 & 0.03 \\
\hline Undecane & 0.06 & 0.11 & 0.05 & 0.04 & 0.05 & 0.05 & 0.02 & 0.01 \\
\hline Ethene & 4.18 & 1.54 & 2.82 & 1.69 & 1.08 & 2.51 & 1.60 & 2.34 \\
\hline Propene & 0.88 & 0.31 & 0.69 & 0.41 & 0.55 & 0.72 & 0.53 & 0.69 \\
\hline 1-butene & 1.17 & 0.78 & 0.59 & 0.48 & 0.95 & 0.34 & 1.62 & 0.91 \\
\hline trans-2-butene & 0.14 & 0.13 & 0.11 & 0.12 & 0.21 & 0.12 & 0.40 & 0.33 \\
\hline cis-2-butene & 0.12 & 0.11 & 0.11 & 0.10 & 0.21 & 0.10 & 0.33 & 0.23 \\
\hline 1-pentene & 0.06 & 0.03 & 0.06 & 0.04 & 0.09 & 0.03 & 0.10 & 0.04 \\
\hline trans-2-pentene & 0.05 & 0.03 & 0.08 & 0.08 & 0.11 & 0.04 & 0.14 & 0.09 \\
\hline cis-2-pentene & 0.05 & 0.03 & 0.05 & 0.04 & 0.08 & 0.04 & 0.09 & 0.05 \\
\hline 1-hexene & 0.04 & 0.05 & 0.12 & 0.08 & 0.12 & 0.03 & 0.11 & 0.03 \\
\hline Acetylene & 4.40 & 1.52 & 2.82 & 2.23 & 1.63 & 0.79 & 2.34 & 1.23 \\
\hline Isoprene & 0.25 & 0.20 & 0.68 & 0.53 & 0.52 & 0.38 & 0.47 & 0.32 \\
\hline Benzene & 1.23 & 0.68 & 0.95 & 0.91 & 0.44 & 0.44 & 0.75 & 0.94 \\
\hline Toluene & 2.53 & 1.03 & 1.95 & 1.56 & 1.36 & 0.41 & 1.01 & 0.53 \\
\hline Ethylbenzene & 0.83 & 0.40 & 0.72 & 0.52 & 0.47 & 0.19 & 0.31 & 0.20 \\
\hline $\mathrm{m} / \mathrm{p}$-xylene & 1.13 & 0.55 & 0.52 & 0.40 & 0.34 & 0.14 & 0.29 & 0.21 \\
\hline o-xylene & 0.32 & 0.14 & 0.31 & 0.23 & 0.20 & 0.07 & 0.15 & 0.09 \\
\hline Styrene & 0.14 & 0.13 & 0.09 & 0.08 & 0.07 & 0.03 & 0.04 & 0.04 \\
\hline Isopropylbenzene & 0.04 & 0.04 & 0.04 & 0.02 & 0.08 & 0.15 & 0.02 & 0.01 \\
\hline propylbenzene & 0.08 & 0.10 & 0.05 & 0.04 & 0.06 & 0.03 & 0.03 & 0.02 \\
\hline m-ethyltoluene & 0.12 & 0.11 & 0.10 & 0.08 & 0.10 & 0.04 & 0.06 & 0.05 \\
\hline p-ethyltoluene & 0.10 & 0.15 & 0.07 & 0.05 & 0.08 & 0.04 & 0.04 & 0.03 \\
\hline 1,3,5-trimethylbenzene & 0.08 & 0.12 & 0.05 & 0.03 & 0.07 & 0.04 & 0.03 & 0.03 \\
\hline o-ethyltoluene & 0.08 & 0.11 & 0.05 & 0.04 & 0.07 & 0.03 & 0.04 & 0.02 \\
\hline 1,2,4-trimethylbenzene & 0.16 & 0.16 & 0.12 & 0.09 & 0.12 & 0.05 & 0.09 & 0.06 \\
\hline 1,2,3-trimethylbenzene & 0.08 & 0.15 & 0.04 & 0.03 & 0.07 & 0.05 & 0.03 & 0.02 \\
\hline 1,3-diethylBenzene & 0.12 & 0.29 & 0.05 & 0.06 & 0.06 & 0.04 & 0.01 & 0.01 \\
\hline 1,4-diethylBenzene & 0.10 & 0.28 & 0.04 & 0.05 & 0.07 & 0.05 & 0.02 & 0.01 \\
\hline
\end{tabular}



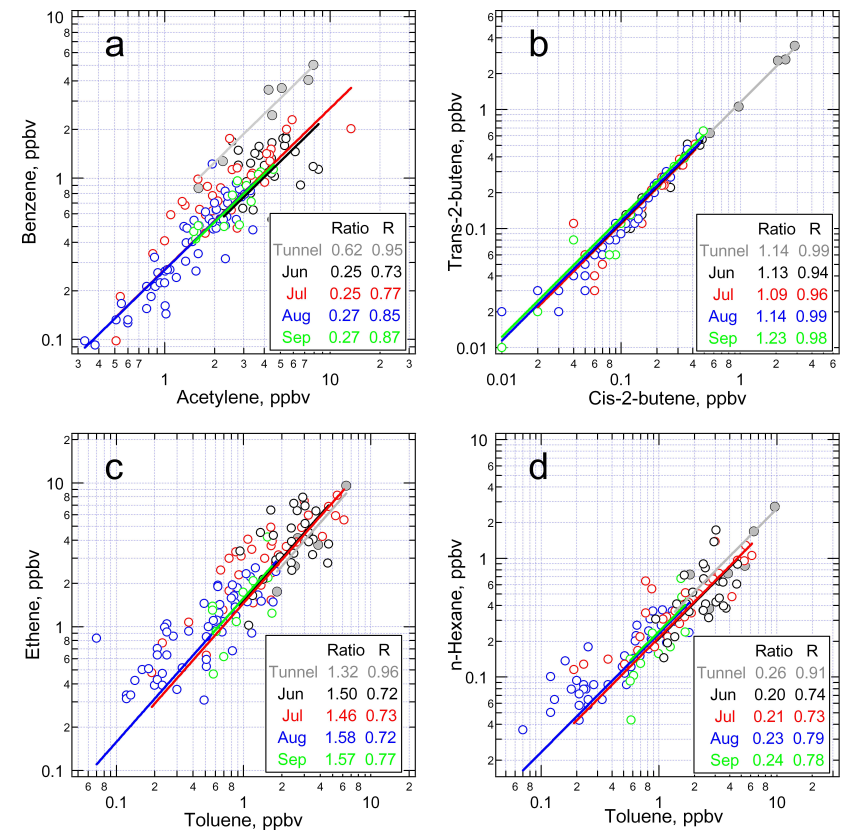

Fig. 4. Ratios and linear correlation coefficients $(R)$ between (a) benzene and acetylene, (b) trans-2-butene and vis-2-butene, (c) ethene and toluene, and (d) n-hexane and toluene during June (in black), July (in red), August (in blue), and September (in green), and comparison with the results of 2009 tunnel study (in grey).

(Fig. 4a-d); the two species in each selected pair have similar rate constants with the $\mathrm{OH}$ radical. The ratios of selected species were derived from the slopes of the linear least-squares fit line.

Figure $4 \mathrm{a}$ shows the correlation between benzene and acetylene. Generally, the ratios were not varied apparently from June to September, with benzene/acetylene ratio of 0.25 in June and July and 0.27 in August and September. These ratios are consistent with the range of $0.21-0.37$ measured at PKU in August 2004 to 2009 (Shao et al., 2009a). Similar situations were also observed in the ratios of trans-2-butene vs. cis-2-butene, ethene vs. toluene, and n-hexane vs. toluene (Fig. 4b-d). These ratios were very close to those measured in a recent tunnel experiment in Beijing (Shao et al., 2009a), and the coefficients are generally higher than 0.7 , indicating that the importance of vehicular emissions was not significantly changed even when the vehicle numbers were reduced by more than half, and reducing emissions from vehicles will require a long-term effort to improve air quality in Beijing city. The much lower ratios of benzene to acetylene in ambient air than that in tunnel experiment, hinting a possible strong background or sources other than vehicle emissions for acetylene, are of interest to be investigated in further studies.
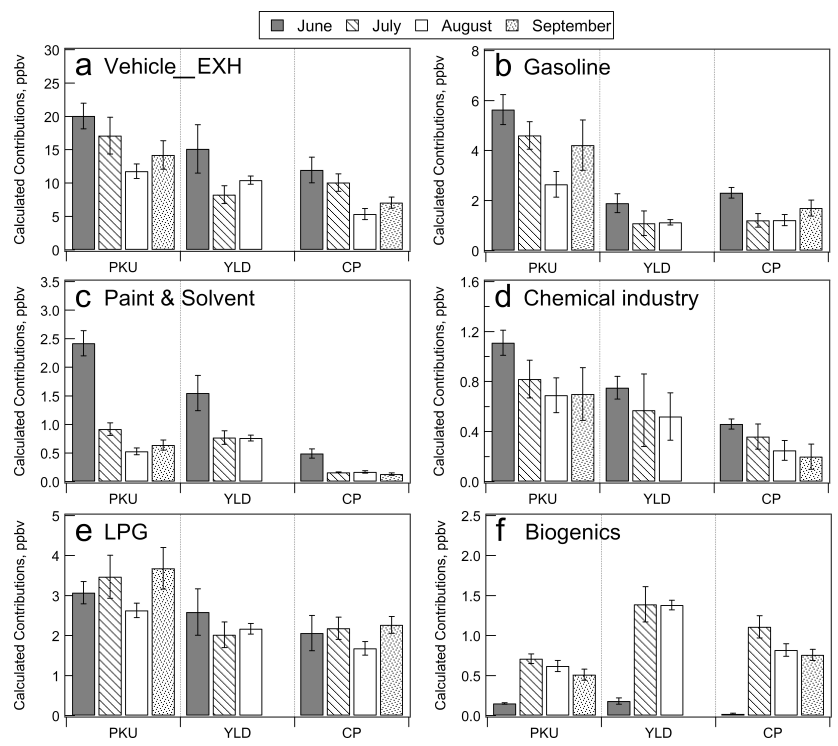

Fig. 5. Calculated contributions from major sources at the three sites: (a) vehicle_EXH, (b) gasoline, (c) paint and solvent, (d) chemical industry, (e) LPG, and (f) biogenics in June, July, August, and September.

\subsection{Reductions in source emissions}

Source apportionments are performed with the CMB model to calculate reductions in source emissions. The source profiles were from measurements on source samples and are summarized in Liu et al. (2008b). As a receptor model, the basic assumption of CMB is that chemical loss for the species is negligible during transport from source to receptor site. Hence, species with atmospheric lifetimes longer than that of toluene were used as fitting species (Table 2). As shown in the calculation, vehicle exhausts (Vehicle_EXH), gasoline evaporation (Gasoline), LPG leakage (LPG), paint and solvent use (Paint \& Solvent), biogenics, and the chemical industry were the major contributors, explaining more than $87 \%$ of the measured NMHCs. The model performance parameters are in the acceptable range, with $R^{2}$ between 0.83 and $0.90, \chi^{2}$ ranging 2.74 to 4.08 , and total calculated concentration (\% Conc.) between $87 \%$ and $98 \%$.

Figure 5 presents calculated contributions from the major sources at the three sites. Vehicle exhaust was the most significant source at all sites, contributing 57-69\% to the ambient NMHCs. The second largest source was LPG (10-19\%), followed by gasoline (7-17\%), biogenics (1-10\%), paint and solvents $(1-8 \%)$, and the chemical industry $(2-4 \%)$. The contribution from vehicle exhaust was more than $59 \%$ of the total contributions at PKU, even in August, indicating that the relative importance of vehicle emissions was not changed even when the traffic was significantly reduced. This is consistent with the results of ratio analysis, revealing the strong source strength of vehicular emissions. 
Vehicles were stepwise controlled in July, August, and September (Table 1). Figure 5a presents the contributions from vehicle_EXH. At PKU, the contribution from vehicle_EXH was about 20 ppbv in June, and it was reduced by $15 \%, 41 \%$, and $29 \%$ in July, August, and September, respectively. These changes were very similar to the changes of traffic flows in the same periods, and the reduction during August was very close to the results estimated using a bottom-up methodology (Zhou et al., 2009). The reductions of vehicle_EXH in July, August, and September contributed $48 \%, 62 \%$, and $65 \%$, respectively, to reductions of ambient NMHCs, reflecting the effectiveness of the control measures. The situation at $\mathrm{CP}$ was similar to that at PKU. The contribution from vehicle_EXH was about $12 \mathrm{ppbv}$ in June and was reduced by $16 \%, 55 \%$, and $41 \%$ in July, August, and September, respectively, and the reductions of vehicle_EXH accounted for $68-70 \%$ of reductions in ambient NMHCs. At YLD, the contribution from vehicle_EXH was about 15 ppbv in June and was reduced by $45 \%$ and $31 \%$ in July and August, respectively. The reductions of vehicle_EXH in July and August corresponded to 62\% and 82\% of reductions in ambient NMHCs. It is interesting that although the odd-even number license plate rule on GLVs was fully implemented in August, the contribution was even slightly higher than in July. This finding again shows that transportation on expressways between Beijing and other cities was a major emitter for YLD, and stringent requirements for vehicles entering Beijing were helpful in cutting the level of NMHCs.

Figure $5 \mathrm{~b}$ shows the calculated contributions from gasoline evaporation, which are actually a combination of contributions from gasoline station and on-road vehicle emissions that are impossible to distinguish with CMB. Emissions from gasoline stations were strictly controlled from 1 July, whereas contributions from on-road vehicles are highly correlated with traffic flows. At PKU site, the contribution was reduced by $18 \%, 53 \%$, and $25 \%$ in July, August, and September, respectively, and was responsible for $17 \%, 22 \%$, and $16 \%$ of the reductions in ambient NMHCs. This variation in pattern is very similar to that of vehicle flows and vehicle_EXH, indicating that vehicles were a major contributor for gasoline evaporation at PKU. At YLD, the contribution was reduced by $31 \%$ and $29 \%$ in July and August, respectively, and was responsible for $9 \%$ and $13 \%$ of the reductions in ambient NMHCs. Because gasoline stations were controlled after 1 July, the comparable contributions in July and August reveal that gasoline stations might be the primary contributor to gasoline evaporation for this site. At CP, the contribution was $2.31 \mathrm{ppbv}$ in June and was reduced by $48 \%$, $47 \%$, and $26 \%$ in July, August, and September, respectively; these reductions were responsible for $40 \%, 11 \%$, and $9 \%$ of the reductions in ambient NMHCs.

From 1 July, paint and solvent use businesses were controlled, and some chemical plants halted production. Contributions from paint and solvent and the chemical industry are given in Fig. 5c and d, both showing apparent decreases after implementation of control measures. From the calculated contributions, on average, emissions from paint and solvent and the chemical industry were reduced by $65-74 \%$ and $24-$ $47 \%$, respectively. The reductions of emissions from paint and solvent corresponded to $14-24 \%$ of the reductions in ambient NMHCs at PKU, 10-15\% at YLD, and 3-15\% at CP, whereas reductions in emissions from the chemical industry corresponded to $3-5 \%$ at PKU, $1-3 \%$ at YLD, and $2-4 \%$ at CP.

Emissions from LPG and biogenics were not targets of the control measures. Figure $5 \mathrm{e}$ and $\mathrm{f}$ presents the contributions from these two sources. As shown in Fig. 5e, contributions from LPG were relatively constant at all sites, contributing about $3 \mathrm{ppbv}$ at PKU and about 2 ppbv at YLD and CP. This distribution is very similar to that of ambient ratios of propane (Fig. 2). Figure $5 f$ shows contributions from biogenic sources, which showed very similar variations in pattern at all sites. Compared to values in June, the source contributions were significantly higher in other months, revealing that the high levels of isoprene measured in these periods mainly contributed to biogenic emissions. This finding is very similar to the results calculated with a bottom-up method (Su et al., 2010; Wang et al., 2003), in which emissions from biogenic sources were predominantly related to ambient temperature and the strength of solar radiation.

\subsection{Ozone formation potentials}

Maximum incremental reactivity (MIR) is the incremental reactivity at a NMHCs/NO $/ \mathrm{x}_{\mathrm{x}}$ ratio which results in the highest ozone formation of the base-case NMHC mixture (Carter, 1994). Ozone formation potentials (OFPs) are then the products by multiplying the ambient mixing ratios of NMHCs and the maximum incremental reactivity (MIR). Because the air quality control measures were also aimed on reducing ambient $\mathrm{O}_{3}$, therefore variations in OFPs were used to investigate the reductions in ozone-forming capability.

Figure 6 shows the average OFPs of alkanes, alkenes, aromatics, acetylene, and isoprene, the sum of which was the average OFP of all measured NMHCs. Compared with the values in June, OFPs of alkanes and acetylene were quite stable, whereas OFPs of alkenes and aromatics were reduced, and OFPs of isoprene significantly increased during the air quality control months (July-September). Based on the above discussions, isoprene came predominantly from biogenic emissions. As the OFP of isoprene constituted a large fraction in July-September, in order to investigate the net effects of the controls, OFPs contributed by isoprene were excluded from the following discussion. The sum of OFPs of alkanes, alkenes, aromatics, and acetylene will be referred as "the total OFP" hereafter.

On average, compared to values in June, the total OFP was reduced by $48 \%$ during the Olympics and $32 \%$ during the Paralympics. These reductions were higher than those 
Table 6. Calculated source contributions to alkenes and aromatics in June, July, August, and September (Unit: ppbv).

\begin{tabular}{|c|c|c|c|c|c|c|c|c|c|c|c|c|}
\hline & & \multicolumn{4}{|c|}{ PKU } & \multicolumn{3}{|c|}{ YLD } & \multicolumn{4}{|c|}{$\mathrm{CP}$} \\
\hline & & Jun & Jul & Aug & Sep & Jun & Jul & Aug & Jun & Jul & Aug & Sep \\
\hline \multirow[t]{7}{*}{ Alkenes } & $\mathrm{V}$ & 7.70 & 6.31 & 4.43 & 5.29 & 5.47 & 3.59 & 4.54 & 4.33 & 3.65 & 1.95 & 2.56 \\
\hline & G & 1.54 & 1.26 & 0.72 & 1.15 & 0.52 & 0.30 & 0.31 & 0.63 & 0.33 & 0.33 & 0.46 \\
\hline & $\mathrm{P}$ & 0.03 & 0.01 & 0.01 & 0.01 & 0.01 & 0.01 & 0.01 & 0.01 & 0.00 & 0.01 & 0.01 \\
\hline & $\mathrm{C}$ & 0.27 & 0.20 & 0.17 & 0.17 & 0.18 & 0.14 & 0.12 & 0.11 & 0.09 & 0.06 & 0.05 \\
\hline & $\mathrm{L}$ & 0.00 & 0.00 & 0.00 & 0.00 & 0.00 & 0.00 & 0.00 & 0.00 & 0.00 & 0.00 & 0.00 \\
\hline & $\mathrm{B}$ & 0.00 & 0.00 & 0.00 & 0.00 & 0.00 & 0.00 & 0.00 & 0.00 & 0.00 & 0.00 & 0.00 \\
\hline & sum & 9.54 & 7.78 & 5.33 & 6.62 & 6.18 & 4.04 & 4.98 & 5.08 & 4.07 & 2.35 & 3.08 \\
\hline \multirow[t]{7}{*}{ Aromatics } & $\mathrm{V}$ & 4.53 & 3.91 & 2.68 & 3.24 & 3.48 & 2.29 & 2.89 & 2.75 & 0.43 & 1.51 & 1.13 \\
\hline & G & 0.38 & 0.31 & 0.18 & 0.28 & 0.13 & 0.08 & 0.08 & 0.16 & 0.07 & 0.07 & 0.04 \\
\hline & $\mathrm{P}$ & 1.36 & 0.52 & 0.30 & 0.36 & 1.03 & 0.51 & 0.50 & 0.28 & 0.24 & 0.18 & 0.20 \\
\hline & $\mathrm{C}$ & 0.39 & 0.29 & 0.24 & 0.24 & 0.27 & 0.21 & 0.19 & 0.16 & 0.04 & 0.07 & 0.09 \\
\hline & $\mathrm{L}$ & 0.00 & 0.00 & 0.00 & 0.00 & 0.00 & 0.00 & 0.00 & 0.00 & 0.00 & 0.00 & 0.00 \\
\hline & B & 0.00 & 0.00 & 0.00 & 0.00 & 0.00 & 0.00 & 0.00 & 0.00 & 0.00 & 0.00 & 0.00 \\
\hline & sum & 6.66 & 5.03 & 3.40 & 4.12 & 4.91 & 3.09 & 3.66 & 3.35 & 0.78 & 1.83 & 1.46 \\
\hline
\end{tabular}

"V" for vehicle_EXH; "G” for gasoline evaporation; "P" for paint \& solvent; "C" for chemical industry; "L" for LPG; "B" for biogenics; and "sum" for total contributions from all sources.

of the ambient mixing ratio of NMHCs, indicating the effectiveness of the air quality controls in reducing ozone-forming capability. Comparing reductions of total OFP with those of alkanes, alkenes, aromatics, and acetylene, it is interesting to note that reductions of the OFP of alkenes contributed 29$51 \%, 19-26 \%$, and $58-62 \%$, whereas reductions of the OFP of aromatics contributed $38-61 \%, 17-44 \%$, and $40-68 \%$ to reductions of total OFP at PKU, YLD, and CP, respectively. As a result, the sum reductions of the OFPs of alkenes and aromatics contributed $83-92 \%, 81-84 \%$, and $77-86 \%$ to reductions of total OFPs at PKU, YLD, and CP, respectively, and were therefore the predominant factor explaining the deceases in total OFP.

Table 6 summarizes the source contributions to alkenes and aromatics in June, July, August, and September based on calculation of CMB. For alkenes, vehicle_EXH was the largest emitter, contributing more than $80 \%$ of ambient alkenes. The second largest source was gasoline evaporation (6-18\%), whereas emissions from other sources were minor. Vehicle_EXH was also the most important emitter of aromatics, contributing $\sim 70 \%$ of ambient mixing ratios, followed by paint and solvent $(\sim 20 \%)$. Emissions from the chemical industry and gasoline evaporation were much smaller. As shown in the table, reductions of vehicle_EXH were the major reason for decreases of the two groups and explain $67-87 \%$ and $38-82 \%$ of reductions of ambient alkenes and aromatics, respectively. Therefore, vehicle controls were the most significant measure in reducing OFPs in Beijing.

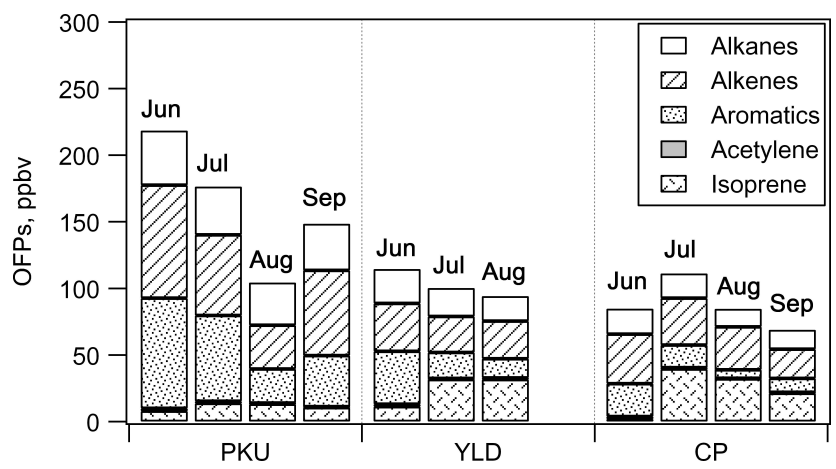

Fig. 6. Average OFPs of measured alkanes, alkenes, aromatics, acetylene, and isoprene at PKU, YLD and CP site from June to September.

\section{Conclusions}

This work demonstrates the effectiveness of the stringent air quality controls implemented by the Beijing municipal government during the summer of 2008. Compared with the levels in June, the mixing ratios of anthropogenic NMHCs were reduced by $35 \%$ and $25 \%$, whereas total OFP values were reduced by $48 \%$ and $32 \%$ during the Olympics and Paralympic Games, respectively. From the results of CMB calculations, contributions from the controlled sources, i.e., vehicle exhaust, gasoline evaporation, paint and solvent use, and the chemical industry, were reduced under the air quality regulations. Among these, controls on vehicles were most effective measure, causing $48-82 \%$ of reductions in ambient NMHCs, 
and they were also the most significant reason for decreases in total OFP. These findings indicate that the stringent air quality restrictions implemented during the 2008 Summer Olympics have been successful, and implementing stringent emission standards on vehicles was the most important measure to improve air quality.

The success of the control measures was also based on taking major emitters in all areas into consideration and implementing specific control options on every emitter. In the typical urban environment of Beijing city, characterized by emissions from GLVs, vehicle restrictions, especially the oddeven license plate rule, were most effective in improving air quality, as shown by the results for the PKU site. In junction areas located near the expressways between Beijing and other cities, implementation of strict requirements for vehicles entering Beijing was most effective in cutting down ambient NMHCs, and hence was also very helpful in cleaning the air inside the city, as shown in the results for the YLD site. In other areas located close to stationary emitters, i.e., paint and solvent use businesses, the chemical industry, gasoline stations, etc., the controls also effectively reduced source emissions, as shown in the calculation of CMB. In municipal areas, decreases in the urban area and source emissions reduce anthropogenic NMHCs, as shown by the results from the CP site. The control measures of 2008 could become an ideal model for future emergent controls to reduce ambient NMHCs in Beijing.

The findings of this study will also provide information for establishing cost-effective policy for abating ground-level $\mathrm{O}_{3}$. Given the fact that NMHCs in Beijing are already at relatively low levels, although $\mathrm{O}_{3}$ pollution has been aggravated in recent years, forming a reactivity-oriented control strategy is urgent. As shown in this study, a large fraction of the total OFP was contributed by alkenes and aromatics, and reduction of vehicle_EXH was the predominant means of reducing ambient alkenes and aromatics. Therefore, controls on vehicles could be a most effective way to deal with $\mathrm{O}_{3}$ pollution and should be top priority in forming future air quality improvement policies. The experience gained in this study could also be valuable for other cities in the world facing air quality problems similar to those in Beijing.

\section{Supplementary material related to this article is available online at: http://www.atmos-chem-phys.net/10/5911/2010/ acp-10-5911-2010-supplement.pdf.}

Acknowledgements. This work was supported by the Beijing Council of Science and Technology project (HB200504-6, HB200504-2), the National High Technology Research and Development Program of China (863 Program, No. 2006AA06A309). The authors thank the science team of the CareBeijing field campaign.

Edited by: D. Parrish

\section{References}

Barletta, B., Meinardi, S., Simpson, I. J., Khwaja, H. A., Blake, D. R., and Rowland, F. S.: Mixing ratios of volatile organic compounds (VOCs) in the atmosphere of Karachi, Pakistan, Atmos. Environ., 36(21), 3429-3443, 2002.

Beijing EPB Environmental Quality Communique: Beijing Municipal Environmental Protection Bureau, available at: http://www. bjepb.gov.cn (last access: January 2010), 1998-2006.

Carter, W. P. L.: Development of ozone reactivity scales for volatile organic compounds, J. Air Waste Manage. Assoc., 44, 881-899, 1994.

Cheng, Y. F., Heintzenberg, J., Wehner, B., Wu, Z. J., Su, H., Hu, M., and Mao, J. T.: Traffic restrictions in Beijing during the Sino-African Summit 2006: aerosol size distribution and visibility compared to long-term in situ observations, Atmos. Chem. Phys., 8, 7583-7594, doi:10.5194/acp-8-7583-2008, 2008.

Goldan, P. D., Parrish, D. D., Kuster, W. C., Trainer, M., McKeen, S. A., Holloway, J., Jobson, B. T., Sueper, D. T., and Fehsenfeld, F. C.: Airborne measurements of isoprene, CO, and anthropogenic hydrocarbons and their implications, J. Geophys. Res.Atmos., 105(D7), 9091-9105, 2000.

Jobson, B. T., Berkowitz, C. M., Kuster, W. C., Goldan, P. D., Williams, E. J., Fesenfeld, F. C., Apel, E. C., Karl, T., Lonneman, W. A., and Riemer, D.: Hydrocarbon source signatures in Houston, Texas: Influence of the petrochemical industry, J. Geophys. Res.-Atmos., 109(D24), D24305, 2004.

Liu, Y., Shao, M., Zhang, J., Fu, L. L., and Lu, S. H.: Distributions and source apportionment of ambient volatile organic compounds in Beijing city, China, J. Environ. Sci. Health A, 40(10), 1843-1860, 2005.

Liu, Ying, Shao, Min, Lu, Sihua, Chang, Chih-chung, Wang, JiaLin, and Chen, Gao: Volatile Organic Compound (VOC) measurements in the Pearl River Delta (PRD) region, China, Atmos. Chem. Phys., 8, 1531-1545, doi:10.5194/acp-8-1531-2008, 2008a.

Liu, Y., Shao, M., Fu, L. L., Lu, S. H., Zeng, L. M., and Tang, D. G.: Source profiles of volatile organic compounds (VOCs) measured in China: Part I., Atmos. Environ., 42, 6247-6260, 2008b.

Lu, S. H., Liu, Y., Shao, M., and Huang, S.: Chemical speciation and anthropogenic sources of ambient volatile organic compounds during summer in Beijing City, Front. Environ. Sci. Engin. China, 1(1), 1-6, 2007.

Shao, M., Tang, X. Y., Zhang, Y. H., and Li, W. J.: City clusters in China: air and surface water pollution, Front. Ecol. Environ., 4(7), 353-361, 2006.

Shao, M., Wang, B., Lu, S. H., Liu, S. C., and Chang, C. C.: Trends in summertime non-methane hydrocarbons in Beijing City, 2004-2009, IGACtivity News Letter, 42, 18-25, 2009a.

Shao, M., Lu, S., Liu, Y., Xie, X., Chang, C., Huang, S., and Chen, Z.: Volatile organic compounds measured in summer in Beijing and their role in ground-level ozone formation, J. Geophys. Res., 114, D00G06, doi:10.1029/2008JD010863, 2009b.

Song, Y., Shao, M., Liu, Y., Lu, S. H., Kuster, W., Goldan, P., and Xie, S. D.: Source apportionment of ambient volatile organic compounds in Beijing, Environ. Sci. Techno., 41(12), 43484353, 2007.

Su, J. H., Shao, M., Lu, S. H., et al.: The NMVOCs emission inventories of Beijing city in the summer of 2008, in preparation, 2010 . 
Tang, G., Li, X., Wang, Y., Xin, J., and Ren, X.: Surface ozone trend details and interpretations in Beijing, 2001-2006, Atmos. Chem. Phys., 9, 8813-8823, doi:10.5194/acp-9-8813-2009, 2009a.

Wang, M., Zhu, T., Zheng, J., Zhang, R. Y., Zhang, S. Q., Xie, X. X., Han, Y. Q., and Li, Y.: Use of a mobile laboratory to evaluate changes in on-road air pollutants during the Beijing 2008 Summer Olympics, Atmos. Chem. Phys., 9, 8247-8263, doi:10.5194/acp-9-8247-2009, 2009.

Wang, T. and Xie, S.: Assessment of traffic-related air pollution in the urban streets before and during the 2008 Beijing Olympic Games traffic control period, Atmos. Environ., 43(35), 56825690, 2009.
Wang, Y., Hao, J., McElroy, M. B., Munger, J. W., Ma, H., Chen, D., and Nielsen, C. P.: Ozone air quality during the 2008 Beijing Olympics: effectiveness of emission restrictions, Atmos. Chem. Phys., 9, 5237-5251, doi:10.5194/acp-9-5237-2009, 2009.

Wang, Z. H., Bai, Y. H., and Zhang, S. Y.: A biogenic volatile organic compounds emission inventory for Beijing, Atmos. Environ., 37, 3771-3782, 2003.

Zhang, Y. H. and Lu, K. D.: The dependence of ozone production rate on ozone precursors in the Beijing and Pearl River Delta regions, 2004-2009, IGACtivity News Letter, 42, 26-38, 2009.

Zhou, Y., Wu, Y., Yang, L., Fu, L., He, K., Wang, S., Hao, J., Chen, J., and Li, C.: The impact of transportation control measures on emission reductions during the 2008 Olympic Games in Beijing, China, Atmos. Environ., 44 (3), 285-293, 2009. 